\title{
Plasma levels of nitric oxide related amino acids in demented subjects with Down syndrome are related to neopterin concentrations
}

\author{
A. M. W. Coppus - D. Fekkes - W. M. A. Verhoeven • \\ S. Tuinier - C. M. van Duijn
}

Received: 19 April 2009/Accepted: 21 April 2009/Published online: 20 May 2009

(C) The Author(s) 2009. This article is published with open access at Springerlink.com

\begin{abstract}
Subjects with Down syndrome (DS) have abnormalities in virtually all aspects of the immune system and almost all will be affected with Alzheimer's disease (AD). It is thought that nitric oxide (NO) is involved in the pathophysiology of $\mathrm{AD}$. In the present study, including a total of 401 elderly DS subjects, the spectrum of plasma amino acids and neopterin was investigated and related to development of $\mathrm{AD}$. Concentrations of nearly all amino acids in DS subjects differed significantly from those of healthy controls. Neopterin was increased in DS subjects, especially in dementia. The production of NO as reflected by an increased citrulline/arginine ratio (Cit/Arg ratio) was enhanced during development of clinical dementia. Neopterin concentrations correlated to the Cit/Arg ratio only in the group of prevalent demented subjects $(\rho=0.48$,
\end{abstract}

\footnotetext{
A. M. W. Coppus ( $₫)$

Centre for the Intellectually Disabled, Dichterbij,

Gennep, The Netherlands

e-mail: a.coppus@erasmusmc.nl
}

A. M. W. Coppus · C. M. van Duijn

Department of Epidemiology,

Erasmus University Medical Centre, Rotterdam,

The Netherlands

D. Fekkes

Department of Neuroscience,

Erasmus University Medical Centre, Rotterdam,

The Netherlands

W. M. A. Verhoeven - S. Tuinier

Vincent van Gogh Institute for Psychiatry,

Venray, The Netherlands

D. Fekkes · W. M. A. Verhoeven

Department of Psychiatry, Erasmus University Medical Centre,

Rotterdam, The Netherlands
$P=0.006)$. The results of this study are suggestive for an increase in oxidative processes in DS subjects with AD.

Keywords Amino acids - Down syndrome - Neopterin · Nitric oxide $\cdot$ Branched chain amino acids

\section{Introduction}

Down syndrome (DS) is a common genetic disorder with a prevalence of 1:750 and is caused by a complete or occasionally partial triplication of chromosome 21 . Its prevalence is highly dependent on maternal age at gestation. It is well known that individuals with DS have an increased rate of congenital and acquired medical complications including among others thyroid gland dysfunction. Abnormalities have been reported in virtually all aspects of the immune system resulting in a greater susceptibility to infectious disease. Finally, they have a higher risk for hematological malignancies, particularly leukemia's, and virtually all show the neuropathological changes of Alzheimer's disease (AD) by the age of 35-40 years. This may be due to an increased production of the amyloid precursor protein (Cheon et al. 2008; Lockstone et al. 2007). Onset of clinical dementia is in general in the first half of the sixth decade. With respect to psychopathology, depression is frequently diagnosed and shows an age related increase (Hunter 2005).

A growing body of evidence indicates that there is an increased oxidative stress in AD brains and it is hypothesized that nitric oxide (NO) can be related to many of the pathophysiological mechanisms of AD (Akomolafe et al. 2006; Moreira et al. 2008). The presence of any stimulant that leads to an overproduction of NO will probably cause neuronal damage (Akyol et al. 2004). The biologically 
active molecule $\mathrm{NO}$ is formed by the conversion of L-arginine to L-citrulline, a reaction catalyzed by the enzyme NO synthase. In this process tetrahydrobiopterin (BH4) is a necessary cofactor. We have shown that the ratio of the plasma concentrations of citrulline (Cit) and arginine (Arg), the so-called Cit/Arg ratio, can be regarded as an index of NO synthesis (Fekkes et al. 2007).

One of the key players in the production of $\mathrm{NO}$ in $\mathrm{AD}$ may be the inflammation and immune activation that characterize the pathology of AD. These processes may play an important role in the development and progression of dementia (McGeer and McGeer 2004). Brain inflammation is mainly caused by activation of glia cells that produce a variety of pro-inflammatory and neurotoxic factors, including free radicals such as NO (Bernstein et al. 2005; Sharma et al. 2007). These processes may also be relevant for persons with DS. We recently found that neopterin, which is an indicator for systemic inflammation and immune activation, increases with age in these subjects and is associated to the risk of dementia (Coppus et al. 2009). Others have found that neopterin is increased in the brain and the plasma of patients with $\mathrm{AD}$ and other neurodegenerative disorders (Hull et al. 2000; Murr et al. 2003).

It has become clear that amino acids are not only essential for various metabolic pathways such as the synthesis of the major neurotransmitters. In addition, amino acids are involved in immune responses (Li et al. 2007; Mircher et al. 1997). Probably of special relevance are the so-called branched-chain amino acids (BCAA) that comprise the three essential amino acids: L-leucine, L-isoleucine and L-valine. In experimental conditions, administration of BCAA was found to improve immune function (Kakazu et al. 2007). In our previous study in healthy DS persons, wide spread differences in nearly all amino acids were found as compared to healthy control subjects with significant lower levels of the essential amino acids (Coppus et al. 2007).

The present study was designed to assess the putative differences in plasma levels of amino acids and neopterin in a large cohort of DS individuals with and without dementia.

\section{Methods}

Study population

Over a period of 4 years a community based sample of 401 individuals with DS, age 45 years and older, from the Southern and South-Western part of the Netherlands was composed. Recruitment procedures and the ethical protocol are described in detail elsewhere (Coppus et al. 2006, 2007). The sample comprises 151 women and 250 males with a mean age of $52 \pm 5.1$ years (Table 1). In 232 subjects, the diagnosis DS was confirmed by cytogenetic analysis. In the remaining, the diagnosis was based on the characteristic phenotype.

The study population was divided into two birth cohorts based on the subject's age at the reference date. The birth

Table 1 General characteristics

\begin{tabular}{|c|c|c|c|c|c|}
\hline & All & Healthy $^{\mathrm{a}}$ & Demented $^{\mathrm{b}}$ & Depression $^{c}$ & Epileptic $^{\mathrm{d}}$ \\
\hline All & 401 persons & 130 & 84 & 38 & 34 \\
\hline \multicolumn{6}{|l|}{$\operatorname{Sex} n(\%)$} \\
\hline Women & $151(37.7)$ & $41(31.5)$ & $32(38.1)$ & $19(50)$ & $11(32.4)$ \\
\hline Men & $250(62.3)$ & $89(68.5)$ & $52(61.9)$ & $19(50)$ & $23(67.6)$ \\
\hline Age start, mean $( \pm \mathrm{SD})$ & $51.6(5.1)$ & $49.9(3.9)$ & $53.2(5.7)$ & $50.3(3.3)$ & 51.3 \\
\hline \multicolumn{6}{|l|}{ Level of ID, $n(\%)$} \\
\hline Severe/profound & $138(34.4)$ & $40(30.8)$ & $34(40.5)$ & $15(39.5)$ & $13(38.2)$ \\
\hline Moderate/mild & $216(53.9)$ & $68(52.3)$ & $46(54.8)$ & $18(47.4)$ & $17(50)$ \\
\hline \multicolumn{6}{|l|}{ Living situation } \\
\hline Institutionalized & 247 (61.6) & $79(60.8)$ & $50(59.5)$ & $32(84.2)$ & $22(64.7)$ \\
\hline Community living & $154(38.4)$ & $51(39.2)$ & $34(40.5)$ & $6(15.8)$ & $12(35.3)$ \\
\hline \multicolumn{6}{|l|}{ Dementia status, $n(\%)$} \\
\hline Demented at the start & $61(15.2)$ & & $30(35.7)$ & & \\
\hline New demented at follow-up & 79 (19.7) & & $54(64.3)$ & & \\
\hline
\end{tabular}

${ }^{a}$ Healthy persons, without dementia, or symptoms of depression and/or epilepsy

b Demented persons without symptoms of depression and/or epilepsy

${ }^{c}$ Depressive persons without symptoms of dementia and/or epilepsy

${ }^{\mathrm{d}}$ Persons with epilepsy, without dementia and/or depressive symptoms 
cohorts distinguishes patients who were 60 years or older (born before $1947 ; n=88$ ) and those who were younger than 60 years (born after 1947; $n=313$ ) at the reference date January 1, 2007. To define syndrome specific differences, the group of subjects with DS $(n=401)$ was compared with a group of 48 age and sex-matched healthy controls of the general population (source lab data, female 16 , male 32, mean age 50.2, SD 9.1 years). For neopterin, data were available for 28 control subjects.

Separate analyses were performed comparing individuals who were demented at baseline (prevalent demented) with those who developed dementia at follow-up (incident demented) and those who remained nondemented during follow-up.

\section{Clinical assessment}

At baseline, assessment included an extensive interview with relatives, caregivers and the responsible physician in order to ascertain the medical history and daily functioning. In addition, all subjects had a thorough physical and neurological examination.

The premorbid level of intellectual disability (ID) was derived from the medical records and classified according to the ICD-10 (World Health Organisation 1992). In addition, a diagnosis of AD was made based on the ICD-10 criteria and the guidelines of the IASSID (Aylward et al. 1997; Burt and Aylward 2000). All subjects were screened annually with a mean follow-up of 4.5 years. Patients who met the diagnostic criteria of $\mathrm{AD}$ at baseline or during follow-up, were monitored every 6 months. A probable diagnosis of depressive disorder was made by the responsible physician or the consultant psychiatrist. Epilepsy was diagnosed by a neurologist or the responsible physician. Level of ID and living situation as an expression of general functioning are presented in Table 1.

The study population was divided into four subgroups according to the presence of only dementia $(n=84)$, only depression $(n=38)$ or only epilepsy $(n=34)$ and healthy DS persons $(n=130)$. The ratio for this subclassification was that the use of anti-epileptics and antidepressants might bias the results. At baseline, of the 401 DS subjects included in this study, 61 had a diagnosis of dementia, of whom 23 with epilepsy. Of the nondemented persons 64 had a diagnosis of epilepsy resulting in a group of 276 nondemented subjects without epilepsy at the start of the study.

\section{Biochemical analyses}

Plasma amino acids were analyzed by high-performance liquid chromatography using pre-column derivatization with $o$-phthaldialdehyde (Fekkes et al. 1995). The tryptophan-ratio was calculated by dividing the total tryptophan level times 100 by the sum of the other large neutral amino acids, i.e., valine, isoleucine, leucine, tyrosine (Tyr) and phenylalanine (Phe), which compete for the transport of tryptophan through the blood-brain barrier. The Tyr ratio was calculated in the same manner by substituting tryptophan for Tyr. The value of aromatic amino acids comprises the summed concentrations Phe, Tyr and tryptophan, and the value of BCAA is the sum of the concentrations of leucine, isoleucine and valine. The Phe/Tyr ratio was calculated to serve as an estimate of BH4 activity. Plasma concentration of neopterin was determined as described previously (Hoekstra et al. 2001).

Amino acids could be measured in 401 subjects and neopterin in 394 subjects

Statistical analysis

Univariate analyses of variance and Chi-square analyses were used to determine whether missing data were associated with age, sex and level of ID; no significant effects were found. In descriptive analyses, data were reported as mean or numbers. Not all data showed normal distribution, and therefore statistical analyses were made using the nonparametric Mann-Whitney $U$ test for comparison of groups. When analyzed as continuous variables, as in the partial correlation analyses, variables were natural log transformed. $P$ values were corrected for multiple comparisons.

\section{Results}

During the follow-up period a total of 80 subjects died, of whom 61 (76.3\%) were demented. As can be inferred from Table 2, plasma concentrations of nearly all biochemical parameters, are significantly different between healthy controls and all individuals with DS. Only a few differences are found in the plasma concentration of the amino acids between the four subgroups, i.e., healthy, demented, depressive and epileptic persons. Significant differences $(P<0.05)$ are found for taurine, phenylalanine and neopterin in that the levels of these parameters are increased in the demented group as compared to the healthy DS group. The increased level of taurine is present mainly in the incident demented group as can been seen in Table 3. In the epileptic subgroup only the tryptophan ratio is found to be decreased as compared to the other subgroups.

From Table 3, it can be inferred that in the group of prevalent demented subjects, excluding those with epilepsy, a significantly higher neopterin concentration $(P=0.05)$ and a lower $\mathrm{Cit} / \mathrm{Arg}$ ratio $(P=0.006)$ are found as compared to the group of nondemented subjects. The plasma concentration of taurine is significantly higher 
Table 2 Comparing the demented, depressive and epileptic persons with Down syndrome with the healthy persons with Down syndrome

\begin{tabular}{|c|c|c|c|c|c|c|}
\hline & $\begin{array}{l}\text { Healthy } \\
\text { controls } \\
n=48\end{array}$ & $\begin{array}{l}\text { All Down } \\
\text { syndrome } \\
n=401\end{array}$ & $\begin{array}{l}\text { Healthy Down } \\
\text { syndrome } \\
n=130\end{array}$ & $\begin{array}{l}\text { Demented Down } \\
\text { syndrome } \\
n=84\end{array}$ & $\begin{array}{l}\text { Depressive Down } \\
\text { syndrome } \\
n=38\end{array}$ & $\begin{array}{l}\text { Epileptic Down } \\
\text { syndrome } \\
n=34\end{array}$ \\
\hline Citrulline $(\mu \mathrm{M})$ & $34.23(8.8)$ & $44.95(13.6)^{\mathrm{a}}$ & $45.89(13.2)$ & $46.90(13.9)$ & $45.42(13.5)$ & $44.50(12.7)$ \\
\hline Arginine $(\mu \mathrm{M})$ & $68.02(24.3)$ & $74.27(21.8)$ & $74.49(21.1)$ & $75.26(19.5)$ & $79.89(30.2)$ & $78.18(19.1)$ \\
\hline Taurine $(\mu \mathrm{M})$ & $42.88(7.6)$ & $52.52(13.0)^{\mathrm{a}}$ & $51.28(12.0)$ & $55.39(12.3)^{\mathrm{b}}$ & $55.00(14.8)$ & $54.00(12.8)$ \\
\hline Tyrosine $(\mu \mathrm{M})$ & $71.04(17.3)$ & $61.77(16.1)^{\mathrm{a}}$ & $61.00(15.2)$ & $64.02(15.5)$ & $63.00(17.1)$ & $63.35(18.5)$ \\
\hline Valine $(\mu \mathrm{M})$ & $286.21(59.7)$ & $232.48(60.1)^{\mathrm{a}}$ & $231.76(60.6)$ & $242.38(60.4)$ & $230.89(54.9)$ & $235.65(50.3)$ \\
\hline Methionine $(\mu \mathrm{M})$ & $32.04(6.4)$ & $24.98(6.2)^{\mathrm{a}}$ & $24.99(5.4)$ & $25.94(7.2)$ & $25.45(6.3)$ & $25.35(6.5)$ \\
\hline Tryptophan $(\mu \mathrm{M})$ & $50.38(9.1)$ & $41.70(10.2)^{\mathrm{a}}$ & $42.83(9.4)$ & $42.89(9.3)$ & $44.29(10.1)$ & $39.79(9.8)$ \\
\hline Phenylanaline $(\mu \mathrm{M})$ & $63.06(9.9)$ & $60.15(14.1)$ & $58.68(12.7)$ & $62.50(13.1)^{\mathrm{b}}$ & $62.53(13.6)^{\mathrm{b}}$ & $60.74(14.9)$ \\
\hline Isoleucine $(\mu \mathrm{M})$ & $82.69(24.1)$ & $64.13(17.5)^{\mathrm{a}}$ & $63.87(17.0)$ & $66.31(18.0)$ & $63.58(17.7)$ & $66.65(14.0)$ \\
\hline Leucine $(\mu \mathrm{M})$ & $148.48(31.8)$ & $125.06(29.3)^{\mathrm{a}}$ & $125.97(28.5)$ & $127.55(29.2)$ & $127.13(30.3)$ & $126.47(23.7)$ \\
\hline Tryptophan ratio & $7.89(1.5)$ & $7.81(1.5)$ & $8.07(1.4)$ & $7.77(1.4)$ & $8.26(1.5)$ & $7.23(1.4)^{\mathrm{b}}$ \\
\hline Tyrosine ratio & $11.33(2.1)$ & $11.98(2.5)$ & $11.82(2.4)$ & $12.01(2.6)$ & $12.03(2.4)$ & $12.12(3.1)$ \\
\hline Phe/Tyr & $0.91(0.1)$ & $0.99(0.2)^{\mathrm{a}}$ & $0.98(0.1)$ & $0.99(0.1)$ & $1.02(0.2)$ & $0.98(0.2)$ \\
\hline Cit/Arg & $0.55(0.2)$ & $0.63(0.2)^{\mathrm{a}}$ & $0.64(0.2)$ & $0.63(0.2)$ & $0.62(0.3)$ & $0.59(0.2)$ \\
\hline Neopterin $(\mathrm{nM})$ & $17.3(3.6)$ & $25.18(11.0)^{\mathrm{a}}$ & $23.40(8.7)$ & $26.35(12.2)^{\mathrm{b}}$ & $24.03(14.9)$ & $24.22(11.5)$ \\
\hline BCAA & $517.37(111.2)$ & $421.67(104.3)^{\mathrm{a}}$ & $421.60(103.8)$ & $436.24(104.7)$ & $421.60(103.8)$ & $428.76(84.9)$ \\
\hline AAA & $184.48(30.2)$ & $163.61(36.3)^{\mathrm{a}}$ & $162.51(34.1)$ & $169.42(34.6)$ & $169.81(36.6)$ & $163.88(37.2)$ \\
\hline LNAA & 701.85 (135.2) & $528.28(133.8)^{\mathrm{a}}$ & $584.11(131.6)$ & $605.65(130.0)$ & $591.42(131.5)$ & $592.64(114.5)$ \\
\hline
\end{tabular}

Values are mean (standard deviation)

Tryptophan ratio tryptophan/LNAA ratio, tyrosine ratio tyrosine/LNAA ratio, Phe/Tyr phenylanaline/tyrosine ratio, Cit/Arg citrulline/arginine ratio, $B C A A$ summed concentration of Leucine, Isoleucine and Valine $\mu \mathrm{M} / 1, A A A$ summed concentration of phenylanaline, tyrosine, tryptophan $\mu \mathrm{M} / \mathrm{l}, L N A A$ large neutral amino acids: summed concentration of phenylalanine, tyrosine, tryptophan, valine, leucine and isoleucine $\mu \mathrm{M} / \mathrm{l}$

${ }^{\text {a }}$ Mann-Whitney $U$-test, $P<0.05$ healthy controls compared with the total group of persons with Down syndrome

${ }^{\mathrm{b}}$ Mann-Whitney $U$-test, $P<0.05$ compared with the group of healthy persons with Down syndrome

in the incident demented as compared with the nondemented $(P=0.002)$ and as compared with the prevalent demented subjects $(P=0.003)$. In the group of incident demented subjects, a significantly higher Cit/Arg ratio is found as compared to the group of prevalent demented subjects $(P=0.003)$.

After adjusting for age, excluding those with epilepsy, there is a high correlation between neopterin and the Cit/ Arg ratio in the group of prevalent demented subjects $(n=38): \rho=0.45 ; P=0.006$, but not in the incident demented cases $(n=64): \rho=0.18 ; P=0.16$ or in the nondemented $(n=276): \rho=0.08 ; P=0.24$. There is a significant correlation between neopterin and the Cit/Arg ratio in the total group of demented subjects $(n=84)$ : $\rho=0.23 ; P=0.04$ ).

By comparing the two age subgroups, born before and after 1947, we see that the concentrations of neopterin and the tyrosine ratio are increased with age whereas the levels of BCAA, taurine and tryptophan are decreased in the older group (data not shown). After controlling for dementia only tryptophan $(\rho=-0.11, P=0.03)$ and neopterin is significantly correlated with age $(\rho=0.18, P<0.001)$.

\section{Discussion}

In the present study, including a large sample of DS subjects with or without dementia, plasma concentrations of nearly all biochemical parameters differ significantly from healthy controls. The decreased tryptophan ratio is explained most likely by the frequent use of anti-epileptics. Concentrations of neopterin and the tyrosine ratio are increased with age whereas the levels of BCAA, taurine and tryptophan are decreased in the older group. These findings are consistent with those reported previously in a small group of healthy DS subjects (Coppus et al. 2007).

With respect to neopterin, a marked increase is found in the total group as compared to healthy controls, that further increases in the demented group. In the group of prevalent dementia the enhanced concentration of neopterin is significantly correlated with a decreased $\mathrm{Cit} / \mathrm{Arg}$ ratio. This finding is may be explained by an increase in oxidative, inflammatory or neurodegenerative processes in dementia. An explanation for a decreased Cit/Arg ratio in this condition may be a reduced bioavailability of $\mathrm{BH} 4$, which is the cofactor for NO synthesis and also for the conversion of 
Table 3 Comparing mean concentrations, nondemented, prevalent demented and incident demented persons with Down syndrome without epilepsy

\begin{tabular}{|c|c|c|c|}
\hline & $\begin{array}{l}\text { Nondemented } \\
\text { at baseline } \\
n=276\end{array}$ & $\begin{array}{l}\text { Prevalent demented } \\
\text { at baseline } \\
n=38\end{array}$ & $\begin{array}{l}\text { Incident demented } \\
\text { during follow-up } \\
n=64\end{array}$ \\
\hline Citrulline $(\mu \mathrm{M})$ & $45.99(13.4)$ & $43.84(13.9)$ & $48.30(13.3)$ \\
\hline Arginine $(\mu \mathrm{M})$ & 73.71 (21.9) & $78.58(19.9)$ & $73.70(19.1)$ \\
\hline Taurine $(\mu \mathrm{M})$ & $52.88(12.6)$ & $49.82(11.8)$ & $56.81(12.8)^{\mathrm{b}, \mathrm{c}}$ \\
\hline Tyrosine $(\mu \mathrm{M})$ & $61.94(15.7)$ & $64.26(18.1)$ & $64.83(13.5)$ \\
\hline Valine $(\mu \mathrm{M})$ & $234.83(60.9)$ & $228.89(62.7)$ & $247.20(56.6)$ \\
\hline Methionine $(\mu \mathrm{M})$ & $25.25(5.9)$ & $25.66(7.7)$ & $26.19(6.4)$ \\
\hline Tryptophan $(\mu \mathrm{M})$ & $43.05(9.5)$ & $41.50(10.6)$ & $43.72(8.1)$ \\
\hline Phenylanaline $(\mu \mathrm{M})$ & $60.57(13.3)$ & $61.74(14.9)$ & $63.09(11.5)$ \\
\hline Isoleucine $(\mu \mathrm{M})$ & $64.49(18.4)$ & $63.05(15.8)$ & $66.97(18.2)$ \\
\hline Leucine $(\mu \mathrm{M})$ & $126.56(30.2)$ & $122.16(27.8)$ & $129.25(28.4)$ \\
\hline Tryptophan ratio & $8.02(1.4)$ & $7.77(1.5)$ & $7.82(1.3)$ \\
\hline Tyrosine ratio & $11.88(2.3)$ & $12.64(3.5)$ & $11.97(1.9)$ \\
\hline Phe/Tyr & $0.99(0.1)$ & $0.98(0.2)$ & $0.98(0.1)$ \\
\hline Cit/Arg & $0.65(0.2)$ & $0.56(0.1)^{\mathrm{a}}$ & $0.66(0.2)^{\mathrm{b}}$ \\
\hline Neopterin (nM) & $24.74(10.1)$ & $28.78(14.4)^{\mathrm{a}}$ & $25.03(9.8)$ \\
\hline $\mathrm{BCAA}(\mu \mathrm{M})$ & $425.87(107.2)$ & $414.10(103.6)$ & $443.42(100.4)$ \\
\hline AAA $(\mu \mathrm{M})$ & $165.56(35.2)$ & $167.50(39.4)$ & $171.64(30.0)$ \\
\hline LNAA $(\mu \mathrm{M})$ & $591.43(136.4)$ & $581.60(129.9)$ & $615.06(124.3)$ \\
\hline
\end{tabular}

Values are mean (standard deviation)

Tryptophan ratio tryptophan/ LNAA ratio, tyrosine ratio tyrosine/LNAA ratio, Phe/Tyr phenylanaline/tyrosine ratio, Cit/Arg citrulline/arginine ratio, $B C A A$ summed concentration of leucine, isoleucine and valine $\mu \mathrm{M} / 1, A A A$ summed concentration of phenylanaline, tyrosine, tryptophan $\mu \mathrm{M} / 1, L N A A$ large neutral amino acids: summed concentration of phenylalanine, tyrosine, tryptophan, valine, leucine and isoleucine $\mu \mathrm{M} / \mathrm{l}$

${ }^{a}$ Mann-Whitney $U$-test, $P<0.05$ prevalent demented compared with the group of nondemented persons with Down syndrome

${ }^{b}$ Mann-Whitney $U$-test, $P<0.05$ incident demented compared with the group of prevalent demented persons with Down syndrome

${ }^{c}$ Mann Whitney $U$-test, $P<0.05$ incident demented compared with the group of nondemented persons with Down syndrome

phenylalanine to tyrosine. This is in line with the increased phenylalanine levels in the demented as compared to the healthy DS subjects. Possible mechanisms for the impaired bioavailability of $\mathrm{BH} 4$ are oxidation of the labile substance $\mathrm{BH} 4$ due to the oxidative stress and/or depletion of BH4 due to the higher neopterin synthesis at the expense of BH4 (Ploder et al. 2008; Shi et al. 2004). Since the Cit/Arg ratio is significantly higher in the incident demented cases and assuming that this ratio is a good reflection of NO synthesis indeed, it can be hypothesized that the production of NO is enhanced during the early development of dementia.

The plasma concentration of taurine is increased especially in the subgroup of incident dementia (Table 3 ). The finding of an increased level of taurine may be syndrome specific since similar observations have been reported previously (Coppus et al. 2007; Mircher et al. 1997). It has been suggested that taurine may prevent neurotoxicity of beta-amyloid (Louzada et al. 2004) and may decrease betaamyloid aggregation (Santa-Maria et al. 2007).
The BCAA concentration is not different in the various subgroups but decreases with age. Since several decades it has been suggested from animal studies that a lower plasma level of BCAA may result in immune impairment (Jose and Good 1973; Li et al. 2007). Whether the observation of diminished BCAA in the group of older DS subjects reflects a syndrome specific impaired immune function is not clear. This may also be the consequence of dietary factors albeit that both in the present study as in the previous one, a large difference between healthy controls and DS subjects was found in the BCAA levels.

In conclusion, the results of the present study demonstrate again that plasma levels of nearly all measured amino acids in DS subjects differ substantially from those in healthy controls. Moreover, in demented DS individuals an additional increase of taurine is observed, while during development of clinical dementia changes in levels of biochemical parameters related to NO metabolism and oxidative stress occur. 
Acknowledgments This research was supported by the Netherlands Organisation for Scientific Research (NWO), de 'Hersenstichting Nederland' and 'Het Jan Jongmanfonds'. The authors are thankful for all Down syndrome persons for their participation in the study. Authors are also indebted to Mrs A.C.C. Voskuilen-Kooijman for her skilled technical assistance.

Open Access This article is distributed under the terms of the Creative Commons Attribution Noncommercial License which permits any noncommercial use, distribution, and reproduction in any medium, provided the original author(s) and source are credited.

\section{References}

Akomolafe A, Lunetta KL, Erlich PM, Cupples LA, Baldwin CT, Huyck M, Green RC, Farrer LA (2006) Genetic association between endothelial nitric oxide synthase and Alzheimer disease. Clin Genet 1(70):49-56. doi:10.1111/j.1399-0004.2006.00638.x

Akyol O, Zoroglu SS, Armutcu F, Sahin S, Gurel A (2004) Nitric oxide as a physiopathological factor in neuropsychiatric disorders. In Vivo 3(18):377-390

Aylward EH, Burt DB, Thorpe LU, Lai F, Dalton A (1997) Diagnosis of dementia in individuals with intellectual disability. J Intellect Disabil Res 41(Pt 2):152-164

Bernstein HG, Heinemann A, Krell D, Dobrowolny H, Bielau H, Keilhoff G, Bogerts B (2005) Hypothalamic nitric oxide synthase in affective disorder: focus on the suprachiasmatic nucleus. Cell Mol Biol (Noisy-le-grand) 3(51):279-284

Burt DB, Aylward EH (2000) Test battery for the diagnosis of dementia in individuals with intellectual disability: working group for the establishment of criteria for the diagnosis of dementia in individuals with intellectual disability. J Intellect Disabil Res 44(Pt 2):175-180

Cheon MS, Dierssen M, Kim SH, Lubec G (2008) Protein expression of BACE1, BACE2 and APP in Down syndrome brains. Amino Acids 35(2):339-343

Coppus A, Evenhuis H, Verberne GJ, Visser F, van Gool P, Eikelenboom P, van Duijn C (2006) Dementia and mortality in persons with Down's syndrome. J Intellect Disabil Res 50(Pt 10):768-777. doi:10.1111/j.1365-2788.2006.00842.x

Coppus AW, Fekkes D, Verhoeven WM, Tuinier S, Egger JI, van Duijn CM (2007) Plasma amino acids and neopterin in healthy persons with Down's syndrome. J Neural Transm 8(114):10411045. doi:10.1007/s00702-007-0656-1

Coppus AM, Fekkes D, Verhoeven WM, Tuinier SA, van Duijn CM (2009) Neopterin and the risk of dementia in persons with Down syndrome. doi:10.1016/j.neulet.2009.04.020

Fekkes D, van Dalen A, Edelman M, Voskuilen A (1995) Validation of the determination of amino acids in plasma by highperformance liquid chromatography using automated pre-column derivatization with $o$-phthaldialdehyde. J Chromatogr B Biomed Appl 2(669):177-186. doi:10.1016/0378-4347(95) 00111-U

Fekkes D, Bannink M, Kruit WH, Van Gool AR, Mulder PG, Sleijfer S, Eggermont AM, Stoter G (2007) Influence of pegylated interferon-alpha therapy on plasma levels of citrulline and arginine in melanoma patients. Amino Acids 1(32):121-126. doi:10.1007/s00726-006-0284-3

Hoekstra R, van den Broek WW, Fekkes D, Bruijn JA, Mulder PG, Pepplinkhuizen L (2001) Effect of electroconvulsive therapy on biopterin and large neutral amino acids in severe, medicationresistant depression. Psychiatry Res 2-3(103):115-123. doi: 10.1016/S0165-1781(01)00282-7

Hull M, Pasinetti GM, Aisen PS (2000) Elevated plasma neopterin levels in Alzheimer disease. Alzheimer Dis Assoc Disord 4(14):228-230. doi:10.1097/00002093-200010000-00007

Hunter AGW (2005) Down syndrome. Wiley-Liss, New Jersey

Jose DG, Good RA (1973) Quantitative effects of nutritional essential amino acid deficiency upon immune responses to tumors in mice. J Exp Med 1(137):1-9. doi:10.1084/jem.137.1.1

Kakazu E, Kanno N, Ueno Y, Shimosegawa T (2007) Extracellular branched-chain amino acids, especially valine, regulate maturation and function of monocyte-derived dendritic cells. J Immunol 10(179):7137-7146

Li P, Yin YL, Li D, Kim SW, Wu G (2007) Amino acids and immune function. $\mathrm{Br} \mathrm{J}$ Nutr 2(98):237-252. doi:10.1017/ S000711450769936X

Lockstone HE, Harris LW, Swatton JE, Wayland MT, Holland AJ, Bahn S (2007) Gene expression profiling in the adult Down syndrome brain. Genomics 6(90):647-660. doi:10.1016/j.ygeno. 2007.08.005

Louzada PR, Lima AC, Mendonca-Silva DL, Noel F, De Mello FG, Ferreira ST (2004) Taurine prevents the neurotoxicity of betaamyloid and glutamate receptor agonists: activation of GABA receptors and possible implications for Alzheimer's disease and other neurological disorders. FASEB J 3(18):511-518. doi: 10.1096/fj.03-0739com

McGeer PL, McGeer EG (2004) Inflammation and the degenerative diseases of aging. Ann N Y Acad Sci (1035):104-116. doi: 10.1196/annals.1332.007

Mircher C, Salabelle A, Peeters MA, Rabier D, Parvy P, Kamoun P, Lejeune J (1997) Variation of amino acids in relation to age in Down syndrome subjects. [Variation des acides amines en fonction de l'age chez des sujets trisomiques 21]. Arch Pediatr 11(4):1093-1099. doi:10.1016/S0929-693X(97)88974-9

Moreira PI, Santos MS, Oliveira CR, Shenk JC, Nunomura A, Smith MA, Zhu X, Perry G (2008) Alzheimer disease and the role of free radicals in the pathogenesis of the disease. CNS Neurol Disord Drug Targets 1(7):3-10

Murr C, Hainz U, Asch E, Berger P, Jenewein B, Saurwein-Teissl M, Grubeck-Loebenstein B, Fuchs D (2003) Association of increased neopterin production with decreased humoral immunity in the elderly. Exp Gerontol 5(38):583-587. doi:10.1016/ S0531-5565(03)00062-7

Ploder M, Neurauter G, Spittler A, Schroecksnadel K, Roth E, Fuchs D (2008) Serum phenylalanine in patients post trauma and with sepsis correlate to neopterin concentrations. Amino Acids 35(2):303-307

Santa-Maria I, Hernandez F, Moreno FJ, Avila J (2007) Taurine, an inducer for tau polymerization and a weak inhibitor for amyloidbeta-peptide aggregation. Neurosci Lett 2-3(429):91-94. doi: 10.1016/j.neulet.2007.09.068

Sharma JN, Al-Omran A, Parvathy SS (2007) Role of nitric oxide in inflammatory diseases. Inflammopharmacology 6(15):252-259. doi:10.1007/s10787-007-0013-x

Shi W, Meininger CJ, Haynes TE, Hatakeyama K, Wu G (2004) Regulation of tetrahydrobiopterin synthesis and bioavailability in endothelial cells. Cell Biochem Biophys 3(41):415-434. doi: 10.1385/CBB:41:3:415

World Health Organization (1992) ICD-10: international statistical classification of diseases and related health problems, 10th revision. WHO, Geneva 